\title{
Opportunities for Classifying the Material Stocks by Several Criteria
}

\author{
Assoc. Prof. PhD Tanka Milkova \\ University of Economics - Varna, Varna, Bulgaria \\ tankamilkova@ue-varna.bg
}

\begin{abstract}
One of the key factors for ensuring the achievement of business aims is related to the proper inventory management in the logistics system. Before moving on to the selection of appropriate methods for optimal management of each specific stock type, it is necessary to classify the whole nomenclature in order of importance according to certain criteria, most often using the methods of analysis ABC and XYZ. Subsequently, appropriate management methods are applied to each of the stock groups. In the specialized literature, the classification of the material stocks by one criterion or the sequential classification of each group by several criteria is most often considered. The present study proposes an approach for constructing an integral nomenclature classification criterion that simultaneously considers the impact of several criteria.
\end{abstract}

Keywords: inventory management, ABC analysis, XYZ analysis.

JEL Code: C61; doi:10.36997/IJUSV-ESS/2019.8.2.11

\section{Въведение}

Управлението на запаси от стоково-материални ценности представлява комплекс от сложни процеси и дейности, които са важен елемент в логистичната система на всяка организация в съвременната икономика. Запасите се срещат във всяка логистична система, тъй като те представляват статичното състояние на материалния поток, а той е основен обект на управление в логистиката. Това обуславя тяхната значимост и е основната причина за непрекъснатия теоретичен и практически интерес към проблемите, свързани с управлението им.

Съгласно общоприетата дефиниция за стоково-материални запаси, те се намират в различни стадии на производството и обрьщението на продукция с производственотехническо предназначение, потребителски и други стоки, очакващи постьпване в производствения процес или потреблението, като се срещат във всички фази на стопанския процес - в снабдяването (суровини, материали, комплектуващи изделия), в производствения процес (незавършена продукция, инструменти, полуфабрикати и др.), в пласмента (готова продукция, резервни части, съпътстващи стоки за сервизите) (Благоев и др., 2009, стр. 356; Димитров и др., 2010, стр. 130-135; Стерлигова, 2012, стр. 7-10).

Наред с основната причина за формиране на стоково-материални запаси, а именно осигуряване на непрекъснатост на дейността (особено при производствени процеси), те осигуряват и редица други предимства на организацията като например: възможност за незабавно обслужване на потребителите, наличие на тьрговски отстьпки за закупуване на големи количества товари, опростяване на процеса на управление на производството, защита от повишаване на цените от нелоялни доставчици и др.

Успоредно с това, наличието на запаси във всички стадии на производството и обръщението, е предпоставка и за натрупване на редица негативи като замразяване на значителен финансов ресурс, ангажиране на човешки ресурси и допълнителни разходи за управление. Според някои изследвания, запасите присъстващи навсякъде в логистичните системи, ангажират до 80\% от оборотните средства на организациите, а разходите по поддържането и управлението им в редица случаи достигат до $40 \%$ от логистичните разходи на фирмите (Благоев и др., 2009, стр. 360).

Фактът, че наличието на запаси в логистичната система има както положителни, така и отрицателни аспекти, обуславя потребността от използването на научно обосновани 
подходи за управление на запасите, с оглед постигане на по-добри икономически резултати. Специализираната и научна литература е богата на различни модели и методи за управление на стоково-материалните запаси, като в зависимост от вида на запаса, мястото на формирането му и характера на потреблението му се препорьчват за използване конкретни методи. Първата стьпка при управлението на запасите обаче е свързана с класифициране на тяхната номенклатура и обособяването им в групи, за всяка от които се препоръчват комплекс от модели и методи за управление. Класическите методи за класифициране на номенклатурата на запасите са известните метод за анализ АBC и метод за анализ XYZ (Дыбская и др., 2008, стр. 594-609; Стерлигова, 2012, стр. 353-376; Сергеев и др., 2005, стр. 535-545; Лукинский и др., 2007, стр. 3-20; Лукинский, 2003, стр. 26-38.), като в литературата са известни някои техни по-нови модификации, например методи за анализ FSN, VED, HML, $\mathrm{SDE} \quad$ и др. (https://www.syntacticsinc.com/news-articles-cat/inventory-analysis-methods/; https://scialert.net/fulltext/?doi=ajava.2018.85.90; https://mywestford.com/blog/fsn-analysis-ininventory-management/; https://www.unleashedsoftware.com/blog/fsn-analysis-can-useful-toolinventory-management). Най-общо същността на тези методи се изразява в определяне на един критерий, според който запасите се разпределят по степен на значимост в три групи и за всяка от групите се прилагат специфични методи за оптимално управление, считани като подходящи за съответната група. Възможно е последователно на няколко етапа да се приложи класифициране на всяка от групите и по други критерии, а сьщо така много често се препоръчва едновременното приложение на методите ABC и XYZ. Това обаче в известна степен затруднява самия процес на класифициране, а и последващия процес на управление.

В настоящата разработка авторът си поставя за цел да представи една възможност за приложение на метода АВС за класифициране на номенклатурата на запасите, при която се използва интегрален критерий, отчитащ едновременно влиянието на няколко критерия обикновено използвани последователно.

\section{1. Същност на методите за класифициране на номенклатурата на стоково- материалните запаси}

Метод за анализ АВС се основава на известното в икономиката правило на Парето или правило 80/20, открито от италианския икономист Вилфредо Парето. Според правилото $80 / 20,20 \%$ от елементите съставляващи дадено явление, обуславят $80 \%$ от неговото проявяване. Това правило може да се интерпретира по следните начини: $20 \%$ от видовете продукция осигуряват $80 \%$ от продажбите от всички видове продукция; 20\% от промишлените предприятия произвеждат $80 \%$ от общия обем на продукцията и др. Широко приложение в логистиката има методът за класифициране, контрол и управление на запасите $\mathrm{ABC}$, основаващ се на правилото на Парето. По отношение на стоково-материалните запаси правилото 80/20 може да се интерпретира по следните начини: 20\% от поддържаните видове запаси са свързани с $80 \%$ от общите разходи за закупуване на всички видове запаси; $20 \%$ от поддържаните видове запаси са свързани с $80 \%$ от общите разходи за управление на всички видове запаси; $20 \%$ от поддържаните видове запаси заемат $80 \%$ от общите складови площи и T.н.

Методът АВС представлява начин за анализ и контрол на състоянието на запасите, който се свежда до разпределяне на номенклатурата на всички стоково-материални запаси на три групи А, В и С на базата на някакъв формален алгоритъм.

Първият етап от приложението на този метод е свързан с избора на критерий за класификация. Критерият за класификация следва да се избере в съответствие с целите на управлението на запасите и може да бъде:

- обща стойност на запасите от всеки вид;

- покупна цена на всеки вид запас;

- разходи по доставката на всеки вид запас, включително транспортни разходи; 
- общи разходи, свързани с всеки вид запас;

- скорост на обръщение на всеки вид запас;

- рентабилност на всеки вид запас;

- размер на складовата площ, заемана от всеки вид запас и др.

Този етап се характеризира с особена трудност и специфика поради факта, че липсва формален алгоритъм, определящ оптималния избор на критерий за класификация. Разчита се на уменията на специалистите по управление на запаси в организацията и тяхната способност да определят най-подходящ критерий в зависимост от поставените цели.

Вторият етап от реализирането на метода АВС е свързан с подреждане на номенклатурата на стоково-материалните запаси в низходящ ред според избрания критерий за класификация. За тази цел е необходимо да се определи значението на всяка позиция от номенклатурата на запасите по избрания критерий за класификация. Например, ако се прави класификация по обща стойност на запасите, следва да се определи паричната обща стойност на запасите от всяка позиция на номенклатурата, която съответства на средното ниво на запасите от този вид и т.н.

На третия етап се осъществява разделяне на номенклатурата на всички запаси в три групи А, В и $\mathrm{C}^{1}$.

Стоково-материалните запаси, които се отнасят към група А са малко на брой (около $20 \%$ ), но представляват преобладаваща част от значението на избрания критерий за класификация (около 80\%). Те имат най-голямо значение в логистичната система, според избрания критерий за класификация, предвид което за тяхното управление следва да се отделят най-голямо внимание и ресурси.

В група В се отнасят стоково-материални запаси, заемащи междинно положение при формиране на номенклатурата на запасите. Те обхващат около $10 \%-15 \%$ от значението на избрания критерий за класификация и представляват около $20 \%-25 \%$ от всички видове запаси в логистичната система. Запасите от група В имат междинно значение в логистичната система, според избрания критерий за класификация.

В група С се отнасят стоково-материални запаси, съставляващи най-голяма част от номенклатурата на стоково-материалните запасите (около 60\%), но ангажиращи незначителна част от значението на избрания критерий за класификация (около $5 \%-10 \%$ ). Запасите от група С имат най-малко значение в логистичната система, според избрания критерий за класификация.

Правилото 80/20 е претьрпяло значителни изменения и сега се срещат различни съотношение - 65/35, 70/30 и т.н. Предвид това дельт на запасите отнасящи се в група А представлява от $10 \%$ до 20\% от номенклатурата на запасите, делът на запасите отнасящи се в група В представлява от $10 \%$ до $30 \%$ от номенклатурата на стоково-материалните запаси, а дельт на запасите отнасящи се в група С представлява от 50\% до $80 \%$ от номенклатурата на запасите. Въпреки това най-голям интерес представлява класифицирането на номенклатурата на запасите по правилото на Парето 80/20, т.е. в група А се отнасят първите $20 \%$ от позициите в пренаредената в низходящ ред номенклатура на стоково-материалните запаси (изразяват около $80 \%$ от проявлението на критерия за класификация), в група В се отнасят следващите $30 \%$ от позициите в пренаредената в низходящ ред номенклатура на стоковоматериалните запаси (изразяват около 15\% от проявлението на критерия за класификация), а в група С се отнасят последните $50 \%$ от номенклатурата на запасите (изразяват около $5 \%$ от проявлението на критерия за класификация).

Така описаният метод за класифициране на номенклатурата на стоково-материалните запаси е известен под наименованието емпиричен метод и въпреки някои свои недостатъци е

\footnotetext{
1 В специализираната литература са посочени конкретни методи и модели, подходящи за управление на запасите от всяка група, но предвид целта на настоящата разработка, тук тези методи няма да бъдат подробно представени.
} 
най-лесен за приложение. В специализираната литература са представени и други методи за определяне на границите между трите групи запаси (диференциален метод и графичен метод) (Лукинский и др., 2007, стр. 3-20; Лукинский, 2003, стр. 26-38.), тъй като всеки от методите има предимства и недостатъци при приложението си, но за целите на настоящото изследване не е необходимо да се спираме подробно и на тях.

Методът за класифициране и анализ АВС има универсален характер в икономиката и може да се използва за класифициране и на други обекти, а не само на запасите от стоковоматериални ценности. Специално за класифициране на номенклатурата на запасите от материални ресурси, незавършено производство и готова продукция е разработен методът XYZ. При този метод отново се прави класификация на запасите на три групи - X, Y и Z. Спецификата се състои в това, че като критерий за класификация тук се използва темпа на потребление и възможността за прогнозиране на търсенето на всеки вид запас. Необходимо е да са налични статистически данни за потреблението на всеки вид запас за определен период от време и това се свързва с известни трудности. Темпът на потребление се оценява с помощта на коефициента на вариация на статистически ред.

Номенклатурата на стоково-материалните запаси отново се разделя на три групи X, Y и Z, като за тях е характерно следното:

Група $\mathrm{X}$ - в нея се отнасят запаси с относително постоянно потребление и възможност за висока точност на прогнозиране на търсенето им. За тази група от номенклатурата на запасите трябва да се използват концепциите за минимизиране на нивото на запасите.

Група Y - в нея се отнасят запаси с предварително известни тенденции в потреблението (например сезонни колебания) и по-малки възможности за прогнозиране на тьрсенето. За тази група от номенклатурата на запасите трябва да се използват концепциите за оптимизиране на нивото на запасите.

Група Z - в нея се отнасят запаси потреблението, на които не може да се характеризира с някаква тенденция и отсъства възможност за прогнозиране на търсенето им или ако има такава възможност, тя е много неточна. За тази група от номенклатурата на запасите могат да се използват концепциите за минимизиране и максимизиране на нивото на запаса, в зависимост от последиците от техния дефицит или наличие в свръх големи количества.

При метода XYZ, както и при метода $\mathrm{ABC}$ се разглеждат различни принципи на класифициране.

1) Към група $X$ могат да се отнесат запаси, които имат коефициент на вариация на потреблението до $25 \%$, в група $\mathrm{Y}$ - от $25 \%$ до $50 \%$ и в група $\mathrm{Z}$ - над $50 \%$.

2) Към група $X$ могат да се отнесат запаси, които имат коефициент на вариация на потреблението до $10 \%$, в група Y - от $10 \%$ до $25 \%$ и в група $\mathrm{Z}$ - над $25 \%$.

3) Към група $X$ могат да се отнесат запаси, които имат коефициент на вариация на потреблението до $15 \%$ - 20\%, в група Y - от $15 \%$ - 20\% до $40 \%-45 \%$ и в група $Z$ - над $40 \%$ $-45 \%$.

Практическото реализиране на класифицирането на номенклатурата на запасите по метода за анализ XYZ може да се направи аналогично на това, при метода ABC, а именно чрез някой от познатите подходи - емпиричен (правило на Парето), диференциален или графичен.

През последните години се наблюдават и някои модификации на методите АВС и $\mathrm{XYZ}$, при които се вземат под внимание повече от един критерия за класифициране на номенклатурата на стоково-материалните запаси чрез тяхното последователно прилагане. Широко разпространено е също така едновременното прилагане на двата метода и разделяне на запасите в девет групи в матрица ABC-XYZ, но това до известна степен усложнява осъществяването на анализа, а от там и самото управление на запасите. 
2. Метод за анализ АВС с интегрален критерий за класифициране на номенклатурата на запасите

В много случаи се налага да се отчете влиянието на повече от един фактор за класифициране на номенклатурата на запасите, тъй като всеки от тях е от съществено значение и оказва влияние върху по-нататъшния избор на оптимална стратегия за управление на запасите. Спецификата при едновременното отчитане на няколко фактора се дължи на обстоятелството, че всеки от тях би могъл да се измерва в различни абсолютни единици. Например: критерият обща стойност на запасите, разходите за тяхното управление и транспортиране се измерват в парична мерна единица (лв.); критерият заемана складова площ може да приема стойности, измерващи се в кв.м./куб.м.; критерият обращаемост може да се измерва в продължителност на един оборот в дни или в брой обороти за определен период от време и т.н. Предвид това в настоящата разработка предлагаме един подход за конструиране на интегрален критерий за класифициране на номенклатурата на стоковоматериалните запаси, при който се използват относителни показатели.

Методът се състои в следното. Приемаме, че номенклатурата на запасите се състои от $m$ елемента, т.е. това е броят на различните видове запаси в организацията (означени с индекс $i=1,2, \ldots, m)$. Трябва да бъде отчетено влиянието на $n$ на брой критерия за класификация (означени с индекс $j=1,2, \ldots, n)$. С $c_{i j}$ се означава стойността на $i$-ти запас от номенклатурата по $j$-ти критерий за класификация (табл. 1).

Таблица 1. Номенклатура на запасите в абсолютни единици

\begin{tabular}{|c|c|c|c|c|c|c|}
\hline \multirow{2}{*}{$\begin{array}{c}\text { Запас } \\
\text { (№ / } \\
\text { наименование) }\end{array}$} & $\begin{array}{c}\text { Сритерий } \\
1\end{array}$ & $\begin{array}{c}\text { Критерий } \\
2\end{array}$ & $\ldots$ & $\begin{array}{c}\text { Критерий } \\
j\end{array}$ & $\ldots$ & $\begin{array}{c}\text { Критерий } \\
n\end{array}$ \\
\hline 1 & $c_{11}$ & $c_{12}$ & $\ldots$ & $c_{1 j}$ & $\ldots$ & $c_{1 n}$ \\
\hline 2 & $c_{21}$ & $c_{22}$ & $\ldots$ & $c_{2 j}$ & $\ldots$ & $c_{2 n}$ \\
\hline$\ldots$ & $\ldots$ & $\ldots$ & $\ldots$ & & $\ldots$ & $\ldots$ \\
\hline$i$ & $c_{i 1}$ & $c_{i 2}$ & $\ldots$ & $c_{i j}$ & $\ldots$ & $c_{i n}$ \\
\hline$\ldots$ & $\ldots$ & $\ldots$ & $\ldots$ & & $\ldots$ & $\ldots$ \\
\hline$m$ & $c_{m 1}$ & $c_{m 2}$ & $\ldots$ & $c_{m j}$ & $\ldots$ & $c_{m n}$ \\
\hline \multirow{2}{*}{ Обща стойност } & $\sum_{i=1}^{m} c_{i 1}$ & $\sum_{i=1}^{m} c_{i 2}$ & $\ldots$ & $\sum_{i=1}^{m} c_{i j}$ & $\ldots$ & $\sum_{i=1}^{m} c_{i n}$ \\
\hline
\end{tabular}

В последния ред на табл. 1 е представена общата стойност на всички запаси от номенклатурата според всеки от критериите за класификация. Преминава се към нови величини $I_{i j}(i=1,2, \ldots, m, j=1,2, \ldots, n)$, представляващи относителния дял (в \%) на $i$-ти запас от номенклатурата от общата стойност на всички запаси по $j$-ти критерий за класификация (табл. 2). Изчисляват се по следния начин:

$$
I_{i j}=\frac{c_{i j}}{\sum_{i=1}^{m} c_{i j}} .100,(i=1,2, \ldots, m, j=1,2, \ldots, n) .
$$




\section{IZVESTIA JOURNAL OF THE UNION OF SCIENTISTS - VARNA}

Таблица 2. Номенклатура на запасите в относителни единици

\begin{tabular}{|c|c|c|c|c|c|c|c|}
\hline $\begin{array}{c}\text { Запас } \\
(\text { № } / \\
\begin{array}{c}\text { наименова } \\
\text { ние) }\end{array}\end{array}$ & $\begin{array}{c}\text { Критерий } \\
1\end{array}$ & $\begin{array}{c}\text { Критерий } \\
2\end{array}$ & $\ldots$ & $\begin{array}{c}\text { Критерий } \\
j\end{array}$ & $\ldots$ & $\begin{array}{c}\text { Критерий } \\
n\end{array}$ & $\begin{array}{c}\text { Интегрален } \\
\text { критерий } \\
I_{i}\end{array}$ \\
\hline 1 & $I_{11}$ & $I_{12}$ & $\ldots$ & $I_{1 j}$ & $\ldots$ & $I_{1 n}$ & $I_{1}=\sum_{j=1}^{n} I_{1 j}$ \\
\hline 2 & $I_{21}$ & $I_{22}$ & $\ldots$ & $I_{2 j}$ & $\ldots$ & $I_{2 n}$ & $I_{2}=\sum_{j=1}^{n} I_{2 j}$ \\
\hline$\ldots$ & $\ldots$ & $\ldots$ & $\ldots$ & & $\ldots$ & $\ldots$ & $\ldots$ \\
\hline$i$ & $I_{i 1}$ & $I_{i 2}$ & $\ldots$ & $I_{i j}$ & $\ldots$ & $I_{i n}$ & $I_{i}=\sum_{j=1}^{n} I_{i j}$ \\
\hline$\ldots$ & $\ldots$ & $\ldots$ & $\ldots$ & & $\ldots$ & $\ldots$ & $\ldots$ \\
\hline$m$ & $I_{m 1}$ & $I_{m 2}$ & $\ldots$ & $I_{m j}$ & $\ldots$ & $I_{m n}$ & $I_{m}=\sum_{j=1}^{n} I_{i j}$ \\
\hline
\end{tabular}

Стойността на интегралния критерий за класификация $I_{i}(i=1,2, \ldots, m)$ за всяка позиция от номенклатурата на запасите се получава като сума на относителните дялове по всеки от отделните критерии за класификация (табл. 2):

$$
I_{i}=\sum_{j=1}^{n} I_{i j},(i=1,2, \ldots, m) .
$$

Освен това, по преценка на специалистите по управление на запаси на всеки отделен критерий за класификация може да се даде различни тегло. С $p_{j}(j=1,2, \ldots, n)$ означаване избраното за целесъобразно тегло на $j$-ти критерий при конструиране на интегралния критерий. Необходимо е $0<p_{j}<1$ и $\sum_{j=1}^{n} p_{j}=1$.

Тогава стойността на интегралния критерий за класификация $I_{i}(i=1,2, \ldots, m)$ за всяка позиция от номенклатурата на запасите се получава като сума на относителните дялове по всеки от отделните критерии за класификация, но коригирани със съответното тегло:

$$
I_{i}=\sum_{j=1}^{n} I_{i j} p_{j},(i=1,2, \ldots, m) .
$$

На следваща стъпка номенклатурата на стоково-материалните запаси се подрежда в низходящ ред според стойността на така получения интегрален показател за класифициране и се прилага правилото на Парето или някой друг от познатите методи за класифициране (диференциален, графичен). По този начин запасите се разпределят в групи А, В и С по степен на важност, като едновременно се отчита значението на всички $n$ критерия за класификация.

Предложеният метод за класифициране на номенклатурата на запасите с интегрален критерий по метода АВС ще бъде демонстриран на базата на примерни числови данни за номенклатура с 20 елемента и конструиране на интегрален критерий за класификация, включващ три отделни критерия (обща стойност в лв., заемана складова площ в кв.м., обращаемост на запасите в брой обороти). Примерните данни са представени в табл. 3. 
ИЗВЕСТИЯ НА СЪЮЗА НА УЧЕНИТЕ - ВАРНА

Таблица 3. Примерна номенклатура на стоково-материалните запаси

\begin{tabular}{|c|c|c|c|}
\hline Запас & Обща стойност в лв. & $\begin{array}{c}\text { Заемана складова площ } \\
\text { в кв.м. }\end{array}$ & $\begin{array}{c}\text { Обращаемост на } \\
\text { запасите в брой обороти }\end{array}$ \\
\hline 001 & 250 & 3 & 5 \\
\hline 002 & 410 & 4 & 11 \\
\hline 003 & 5200 & 7,4 & 14 \\
\hline 004 & 140 & 9 & 4 \\
\hline 005 & 20 & 3,4 & 4 \\
\hline 006 & 400 & 1 & 3 \\
\hline 007 & 120 & 0,5 & 2 \\
\hline 008 & 200 & 0,8 & 3 \\
\hline 009 & 320 & 1,2 & 6 \\
\hline 010 & 750 & 1,3 & 3 \\
\hline 011 & 4700 & 2,3 & 5 \\
\hline 012 & 920 & 1,3 & 4 \\
\hline 013 & 530 & 1,8 & 9 \\
\hline 014 & 420 & 2 & 5 \\
\hline 015 & 120 & 1,4 & 4 \\
\hline 016 & 300 & 1,5 & 7 \\
\hline 017 & 560 & 1,5 & 6 \\
\hline 018 & 3800 & 2 & 3 \\
\hline 019 & 150 & 1,5 & \\
\hline 020 & 120 & 2,5 & 6 \\
\hline & & & 2 \\
\hline
\end{tabular}

Пьрвоначално е представено класифицирането на номенклатурата на запасите по метода $\mathrm{ABC}$ по всеки един от трите критерия поотделно. Номенклатурата е подредена в низходящ ред по стойността на съответния критерий и е разделена по правилото на Парето, като в група А са включени първите $20 \%$ от елементите в номенклатурата, т.е. пьрвите 4 запаса, в група В са включени следващите 30\% от елементите в номенклатурата, т.е. следващите 6 запаса и в група С са включени последните 50\% от елементите в номенклатурата, т.е. последните 10 запаса. Резултатите са представени в табл. 4.

Таблица 4. Класификация на номенклатурата по метод АВС по отделни критерии

\begin{tabular}{|c|c|c|c|c|c|c|}
\hline Запас & $\begin{array}{c}\text { Обща } \\
\text { стойност в } \\
\text { лв. }\end{array}$ & Запас & $\begin{array}{c}\text { Заемана } \\
\text { складова площ в } \\
\text { кв.м. }\end{array}$ & Запас & $\begin{array}{c}\text { Обращаемост на } \\
\text { запасите в брой } \\
\text { обороти }\end{array}$ & Група \\
\hline 003 & 5200 & 004 & 9 & 003 & 14 & $\mathrm{~A}$ \\
\hline 011 & 4700 & 003 & 7,4 & 002 & 11 & $\mathrm{~A}$ \\
\hline 018 & 3800 & 002 & 4 & 015 & 9 & $\mathrm{~A}$ \\
\hline 012 & 920 & 005 & 3,4 & 004 & 8 & $\mathrm{~A}$ \\
\hline 010 & 750 & 001 & 3 & 018 & 7 & $\mathrm{~B}$ \\
\hline 017 & 560 & 020 & 2,5 & 011 & 6 & $\mathrm{~B}$ \\
\hline 013 & 530 & 011 & 2,3 & 019 & 6 & $\mathrm{~B}$ \\
\hline 014 & 420 & 014 & 2 & 013 & 5 & $\mathrm{~B}$ \\
\hline 002 & 410 & 018 & 2 & 016 & 5 & $\mathrm{~B}$ \\
\hline 006 & 400 & 013 & 1,8 & 001 & 5 & $\mathrm{C}$ \\
\hline 009 & 320 & 016 & 1,5 & 005 & 4 & $\mathrm{C}$ \\
\hline 016 & 300 & 017 & 1,5 & 006 & 4 & \\
\hline
\end{tabular}


IZVESTIA JOURNAL OF THE UNION OF SCIENTISTS - VARNA

\begin{tabular}{|l|c|c|c|c|c|c|}
\hline 001 & 250 & 019 & 1,5 & 014 & 4 & $\mathrm{C}$ \\
\hline 008 & 200 & 015 & 1,4 & 017 & 4 & $\mathrm{C}$ \\
\hline 019 & 150 & 010 & 1,3 & 007 & 3 & $\mathrm{C}$ \\
\hline 004 & 140 & 012 & 1,3 & 009 & 3 & $\mathrm{C}$ \\
\hline 007 & 120 & 009 & 1,2 & 012 & 3 & $\mathrm{C}$ \\
\hline 015 & 120 & 006 & 1 & 020 & 3 & $\mathrm{C}$ \\
\hline 020 & 120 & 008 & 0,8 & 008 & 2 & $\mathrm{C}$ \\
\hline 005 & 20 & 007 & 0,5 & 010 & 2 & $\mathrm{C}$ \\
\hline
\end{tabular}

В табл. 5 е показано конструирането на интегралния критерий за класификация на база описания метод, както без да се налагат някакви тегла на отделните критерии, така и при положение, че са определени тегла на всеки от критериите, съответно $p_{1}=0,4, p_{2}=0,1$ и $p_{3}=0,5$.

Таблица 5. Конструиране на интегрален показател за класификация

\begin{tabular}{|c|c|c|c|c|c|}
\hline Запас & $\begin{array}{c}\text { Относителен } \\
\text { дял на обща } \\
\text { стойност (\%) }\end{array}$ & $\begin{array}{c}\text { Относителен дял на } \\
\text { заеманата складова } \\
\text { площ (\%) }\end{array}$ & $\begin{array}{c}\text { Относителен } \\
\text { дял на броя на } \\
\text { оборотите (\%) }\end{array}$ & $\begin{array}{c}\text { Интегрален } \\
\text { критерий за } \\
\text { класификация }\end{array}$ & $\begin{array}{c}\text { Претеглен } \\
\text { интегрален } \\
\text { критерий за } \\
\text { класификация }\end{array}$ \\
\hline 001 & 1,29 & 6,07 & 4,63 & 11,99 & 3,44 \\
\hline 002 & 2,11 & 8,10 & 10,19 & 20,39 & 6,75 \\
\hline 003 & 26,76 & 14,98 & 12,96 & 54,71 & 18,68 \\
\hline 004 & 0,72 & 18,22 & 7,41 & 26,35 & 5,81 \\
\hline 005 & 0,10 & 6,88 & 3,70 & 10,69 & 2,58 \\
\hline 006 & 2,06 & 2,02 & 3,70 & 7,79 & 2,88 \\
\hline 007 & 0,62 & 1,01 & 2,78 & 4,41 & 1,74 \\
\hline 008 & 1,03 & 1,62 & 1,85 & 4,50 & 1,50 \\
\hline 009 & 1,65 & 2,43 & 2,78 & 6,85 & 2,29 \\
\hline 010 & 3,86 & 2,63 & 1,85 & 8,34 & 2,73 \\
\hline 011 & 24,19 & 4,66 & 5,56 & 34,40 & 12,92 \\
\hline 012 & 4,73 & 2,63 & 2,78 & 10,14 & 3,55 \\
\hline 013 & 2,73 & 3,64 & 4,63 & 11,00 & 3,77 \\
\hline 014 & 2,16 & 4,05 & 3,70 & 9,91 & 3,12 \\
\hline 015 & 0,62 & 2,83 & 8,33 & 11,78 & 4,70 \\
\hline 016 & 1,54 & 3,04 & 4,63 & 9,21 & 3,24 \\
\hline 017 & 2,88 & 3,04 & 3,70 & 9,62 & 3,31 \\
\hline 018 & 19,56 & 4,05 & 6,48 & 30,09 & 11,47 \\
\hline 019 & 0,77 & 3,04 & 5,56 & 9,36 & 3,39 \\
\hline 020 & 0,62 & 5,06 & 2,78 & 8,46 & 2,14 \\
\hline
\end{tabular}

След пренареждане на номенклатурата в низходящ ред според стойността на интегралния критерий за класифициране и приложение на правилото на Парето, запасите се разделят според степен на важност в групи A, B, C, а резултатите са представени в табл. 6.

\footnotetext{
${ }^{2}$ Специално при този критерий би могло да се използва отношението на индивидуалната обращаемост в брой обороти на всеки запас към обращаемостта в брой обороти на запасите в организацията като цяло. Броят на оборотите се определя като частно на стойността на потребените запаси от всички видове и стойността на средния обем на запаса от всички видове.
} 
Таблица 6. Класификация на номенклатурата по метод АВС според интегралния критерий за класификация

\begin{tabular}{|c|c|c|c|c|}
\hline Запас & $\begin{array}{c}\text { Стойност на } \\
\text { интегралния критерий } \\
\text { за класификация }\end{array}$ & Запас & $\begin{array}{c}\text { Стойност на претегления } \\
\text { интегралния критерий за } \\
\text { класификация }\end{array}$ & Група \\
\hline 003 & 54,71 & 003 & 18,68 & $\mathrm{~A}$ \\
\hline 011 & 34,40 & 011 & 12,92 & $\mathrm{~A}$ \\
\hline 018 & 30,09 & 018 & 11,47 & $\mathrm{~A}$ \\
\hline 004 & 26,35 & 002 & 6,75 & $\mathrm{~A}$ \\
\hline 002 & 20,39 & 004 & 5,81 & $\mathrm{~B}$ \\
\hline 001 & 11,99 & 015 & 4,70 & $\mathrm{~B}$ \\
\hline 015 & 11,78 & 013 & 3,77 & $\mathrm{~B}$ \\
\hline 013 & 11,00 & 012 & 3,55 & $\mathrm{~B}$ \\
\hline 005 & 10,69 & 001 & 3,44 & $\mathrm{~B}$ \\
\hline 012 & 10,14 & 019 & 3,39 & $\mathrm{~B}$ \\
\hline 014 & 9,91 & 017 & 3,31 & $\mathrm{C}$ \\
\hline 017 & 9,62 & 016 & 3,24 & $\mathrm{C}$ \\
\hline 019 & 9,36 & 014 & 3,12 & $\mathrm{C}$ \\
\hline 016 & 9,21 & 006 & 2,88 & $\mathrm{C}$ \\
\hline 020 & 8,46 & 010 & 2,73 & $\mathrm{C}$ \\
\hline 010 & 8,34 & 005 & 2,58 & $\mathrm{C}$ \\
\hline 006 & 7,79 & 009 & 2,29 & $\mathrm{C}$ \\
\hline 009 & 6,85 & 020 & 2,14 & $\mathrm{C}$ \\
\hline 008 & 4,50 & 007 & 1,74 & $\mathrm{C}$ \\
\hline 007 & 4,41 & 008 & 1,50 & $\mathrm{C}$ \\
\hline
\end{tabular}

Въз основа на така получените резултати специалистите по управление на запаси в логистичната система могат да направят своите изводи и анализи, които да очертаят насоките и да посочат правилните методи за оптимално управление на запасите от всяка група. По отношение на запасите от група А, които представляват най-голям интерес за организацията, може да се каже, че е от голямо значение избраният критерий за класификация. При отчитане например само на стойността на запасите се установява, че найважни за организацията са тези под номера 003, 011, 018 и 012. При положение, че се вземат предвид и другите критерии за класифициране, без да им се задава тегла, съставът на запасите в група А се променя, като там следва да се включи запас под номер 004 на мястото на запас под номер 012. Ако по преценка на специалистите по управление на запаси се въведат тегла на всеки от критериите се установява, че в състава на група А, вместо запас под номер 012, трябва да се включи запас под номер 002. Напълно се променя положението, ако бъде определен като най-важен признак за класифициране на запасите например тяхната обращаемост. Тогава, без значение от общата им стойност и заемана складова площ, като най-важни и подлежащи на непрекъснат контрол и управление следва да се разглеждат запаси под номера 002, 003, 004 и 015.

Крайното решение следва да се вземе на база получените резултати, но в зависимост от спецификата на дейността на конкретната организация и съобразно поставените бизнес цели, свързани с управлението на стоково-материалните запаси.

\section{Заключение}

Предложената модификация на метода за анализ и класифициране на номенклатурата на запасите $\mathrm{ABC}$ чрез едновременно отчитане на няколко критерия за класифициране 
предоставя допълнителни възможности за изучаване на запасите и на тази основа определяне на подходящи методи и модели за тяхното оптимално управление. Разбира се, това не е универсално решение на проблема с класифициране на номенклатурата на запасите, но обогатява теоретичните постановки по темата и в редица случаи би могло да подпомогне процеса на вземане на управленски решения, и подобряване на икономическите резултати.

\section{References}

1. Blagoev, Bl. i dr. (2009) Stopanska logistika. Varna: Nauka i ikonomika.

2. Dimitrov, P. i dr. (2010) Logistichni sistemi. Sofiya: Stopanstvo.

3. Daybskaya, V. V. i dr. (2008) Logistika. Integratsiya i optimizatsiya logisticheskih biznesprotsesov v tsepyah postavok. Moskva: Eksmo.

4. Lukinskiy, V. S. i dr. (2007) Logistika v primerah i zadach. Moskva: Finansay i statistika.

5. Lukinskiy, V. S. (2003) Modeli i metodi teorii logistiki. Sankt-Peterburg: Piter.

6. Sergeev, V. I. i dr. (2005) Korporativnaya logistika. 300 otvetov na voprosay professionalov. Moskva: INFRA-M.

7. Sterligova, A. N. (2012) Upravlenie zapasami v tsepyah postavok. Moskva: Infra-M.

8. https://mywestford.com/blog/fsn-analysis-in-inventory-management/ [Accessed 23/08/2019].

9. https://scialert.net/fulltext/?doi=ajava.2018.85.90 [Accessed 23/08/2019].

10. https://www.syntacticsinc.com/news-articles-cat/inventory-analysis-methods/ 23/08/2019].

11. https://www.unleashedsoftware.com/blog/fsn-analysis-can-useful-tool-inventory-management [Accessed 23/08/2019]. 